\title{
Grismadox gen. nov., a new Neotropical genus of ant-resembling spiders (Araneae, Corinnidae, Castianeirinae), including the description of two new species from Bolivia and Paraguay
}

\author{
Brogan L. Pett ${ }^{1,2,3}$, Gonzalo D. Rubio ${ }^{4,5}$, Robert Perger ${ }^{6}$ \\ 1 Colección Cientifica Para La Tierra, 321 Mariscal Estigarribia, Pilar, Neembucú, Paraguay \\ 2 Centre for Ecology and Conservation, College of Life and Environmental Sciences, University of Exeter, Penryn Campus, Penryn, Cornwall, \\ TR10 9FE, UK \\ 3 SpiDivERse, Biodiversity Inventory for Conservation (BINCO), Walmersumstraat 44, 3380 Glabbeek, Belgium \\ 4 Consejo Nacional de Investigaciones Científicas y Técnicas (CONICET), Cerro Azul, Misiones, Argentina \\ 5 Estación Experimental Agropecuaria Cerro Azul (EEA CA, INTA), Cerro Azul, Misiones, Argentina \\ 6 Colección Boliviana de Fauna, La Paz, Bolivia
}

http://zoobank.org/CA75C8DB-013E-42D3-920F-654890CAFCAC

Corresponding author: Brogan L. Pett (brogan.pett@outlook.com)

Academic editor: Danilo Harms • Received 17 October 2021 • Accepted 3 December 2021 • Published 7 January 2022

\begin{abstract}
A new genus and two new species of ant-resembling castianeirine spiders are described from the Neotropics. Grismadox gen. nov. comprises four species: Grismadox baueri sp. nov., and Grismadox mazaxoides (Perger \& Duperré, 2021) comb. nov. from Bolivia, and Grismadox karugua sp. nov. (type species) and Grismadox mboitui (Pett, 2021) comb. nov. from Paraguay. All species are diagnosed and the new species are described and illustrated. Available ecological data suggests that all four species are primarily epigeal and inhabit Grassland and savannah type habitats.
\end{abstract}

\section{Key Words}

ant-mimic, Chiquitano, Humid Chaco, myrmecomorph

\section{Introduction}

The subfamily Castianeirinae (Araneae, Corinnidae) is represented by slender spiders generally regarded as good examples of Batesian or Müllerian mimics of ants (Cushing 2012; Perger and Rubio 2020; Perger 2021). The subfamily is cosmopolitan and the New World has a rich fauna of accurate ant mimics with similar coloration to their ant models and adaptations to the typical body plan (according to concepts of Pekár and Jarab 2011). New World endemic genera include Mazax O. Pickard-Cambridge, 1898, Myrmecium Latreille, 1824, Myrmecotypus O. Pickard-Cambridge, 1894 and Psellocoptus Simon, 1896 (World Spider Catalog 2021). The genera Apochinomma Pavesi, 1881, Castianeira Keyserling, 1879 and Spheco- typus O. Pickard-Cambridge, 1895 are recorded from the New World, but have intercontinental distributions, being registered from the Oriental Region, and the former two also from the Afrotropical realm (Haddad 2013; World Spider Catalog 2021). However, Apochinomma may be restricted to the Afrotropical realm, with Neotropical representatives likely misplaced (Rubio and Arbino 2009).

Castianeirines are notorious for having highly conserved genitalic characters (Rubio et al. 2015), with both sexes showing a reduction or absence of various structures typically found in related families of dionychan spiders (Ramírez 2014). However, in contrast to the genera Myrmecium and Mazax, which appear to be monophyletic (Reiskind 1969; Candiani and Bonaldo 2017), the variation in male genitalic structure of Myrmecotypus suggests a polyphyletic group 
(Reiskind 1969; Perger and Rubio 2020). The level of variation exhibited in the embolus shape, length, and trajectory, as well as the presence or absence of a large to small conductor, retrolateral tibial apophyses (RTAs) of various sizes, including some large and distinct RTAs (Reiskind 1969; Pett 2021a), alludes to the hitherto undescribed generic diversity within the group. In contrast, female genitalia have always been described as relatively uniform in Myrmecotypus, with copulatory ducts joining the secondary spermathecae (ST II) and projecting posterolaterally (Reiskind 1969; Rubio and Arbino 2009; Perger and Rubio 2020).

In the current study, two new castianeirine species are described from Bolivia and Paraguay. These species share a combination of several somatic and genitalic characters with Myrmecotypus mboitui Pett, 2021 and M. mazaxoides Perger \& Dupérré, 2021 that is not found in other Neotropical castianeirines. The similarities between these four species and differences to Myrmecotypus species warrant the establishment of a new genus, herein described.

\section{Materials and methods}

Material is preserved in $70 \%$ ethanol. The epigyne was dissected using a custom-made hooked pin and digested by submersion in a glass vial filled with lactic acid, which was placed in boiling water for around thirty minutes. The cleared epigyne was temporarily prepared on a slide and examined with a compound microscope. Examinations were carried out with an AmScope ZM-4T stereomicroscope or an Olympus BX61. Images were taken using either a Leica M125C automontage system or an Olympus BX61 with a DP74 camera. All images were Z-stacked, with between 10-30 images merged into a single photomontage, using Helicon Focus 6.7 (www.heliconsoft.com). Habitus illustrations were made by BLP using a 'Wacom One' graphics tablet with images underlaid at $60 \%$ opacity on the program 'Autodesk Sketchbook' (see: Cala-Riquelme 2021). Images were adjusted in Adobe Photoshop version 21.0.1 for contrast and white balance. Plates were also composed in Adobe Photoshop.

The following indices are used following Reiskind (1969): A) carapace index = carapace width/ carapace length $\times 100 ;$ B) cephalic index $=$ cephalic width $/$ carapace width $\times 100 ;$ C) sternum index $=$ sternum width/ sternum length $\times 100 ;$ D) abdomen index $=$ abdomen width/ abdomen length $\times 100$. All measurements are in millimetres. The type species is treated first with the remaining species treated alphabetically.

Leg spination follows Rubio and Danisman (2014), with $\mathbf{d}=$ dorsal; $\mathbf{p l}=$ prolateral; $\mathbf{p l v}=$ prolateral ventral; $\mathbf{r l}=$ retrolateral; $\mathbf{r l v}=$ retrolateral ventral; $\mathbf{v}=$ ventral. Other morphological terminology is standard for arachnology, with castianeirine specifics from Reiskind (1969). Abbreviations used in the text: $\mathbf{A E R}=$ anterior eye row; $\mathbf{A I}=$ abdomen index; $\mathbf{A L}=$ abdomen length; $\mathbf{A L E}=$ anterior lateral eyes; $\mathbf{A M E}=$ anterior median eyes; $\mathbf{A W}=$ abdomen width; $\mathbf{B L}$ = body length; $\mathbf{C D}=$ copulatory duct $; \mathbf{C I}=$ carapace index;
$\mathbf{C L}=$ carapace length; $\mathbf{C O}=$ copulatory opening; $\mathbf{C W}=$ carapace width; dRTA = dorsal retrolateral tibial apophysis; FD = fertilization duct; $\mathbf{P E R}=$ posterior eye row; PLE $=$ posterior lateral eyes; $\mathbf{P M E}=$ posterior median eyes; $\mathbf{S I}$ = sternum index; $\mathbf{S L}=$ sternum length; $\mathbf{S T}=$ spermathecae (ST I is the most posterior (from which the fertilization ducts originate), ST II is the most anterior (into where the copulatory ducts enter); $\mathbf{S W}=$ sternum width; $\mathbf{v R T A}=$ ventral retrolateral tibial apophysis. Legs I-IV = leg numbers.

Arachnological collections are abbreviated as follows (curators in parenthesis):

CBF Colección Boliviana de Fauna, La Paz, Bolivia (R. Perger);

CIPLT-Ar Colección Científica Para La Tierra- Aracnología (G. Hicks);

SMNK Staatliches Museum für Naturkunde, Karlsruhe, Germany (H. Höfer).

ZMH Zoological Museum Hamburg, University of Hamburg, Germany (D. Harms).

Nomenclatural acts. This published work and the nomenclatural acts it contains have been registered in Zoobank: http://zoobank.org/References/893A7CA0-CFB1-4687-960B-24D54B863C6C. http:// zoobank.org/References/9EE84FF4-0803-487E-899797C7097007E2. http://zoobank.org/References/1EB5BA81-86AF-48C3-B0FF-040C722F4D6F. The LSID for this publication is: urn:lsid:zoobank.org:pub:CA75C8DB-013E-42D3-920F-654890CAFCAC.

\section{Ecoregion distribution}

The ecoregion affinities of the species were investigated by visualizing the coordinates and a shapefile of the regionalization of Neotropical ecosystems by Olson et al. (2001), by using the geographic information system QGIS (version 2.14.3, http://www.qgis.org/en/site/) (Fig. 1). Coordinates of the collection locality for $G$. baueri sp. nov. were approximated according to information from the owner of Espiritu ranch. Geographic coordinates are shown in decimal degrees with reference datum WGS84, and elevation in meters above sea level (m a.s.1.).

\section{Results}

\section{Family Corinnidae Karsch, 1880 Subfamily Castianeirinae Reiskind, 1969}

\section{Genus Grismadox gen. nov.}

http://zoobank.org/893A7CA0-CFB1-4687-960B-24D54B863C6C

Type species. Grismadox karugua sp. nov.

Etymology. The genus name is a patronym in honor of Cristian Grismado, arachnologist of Museo Argentino de 


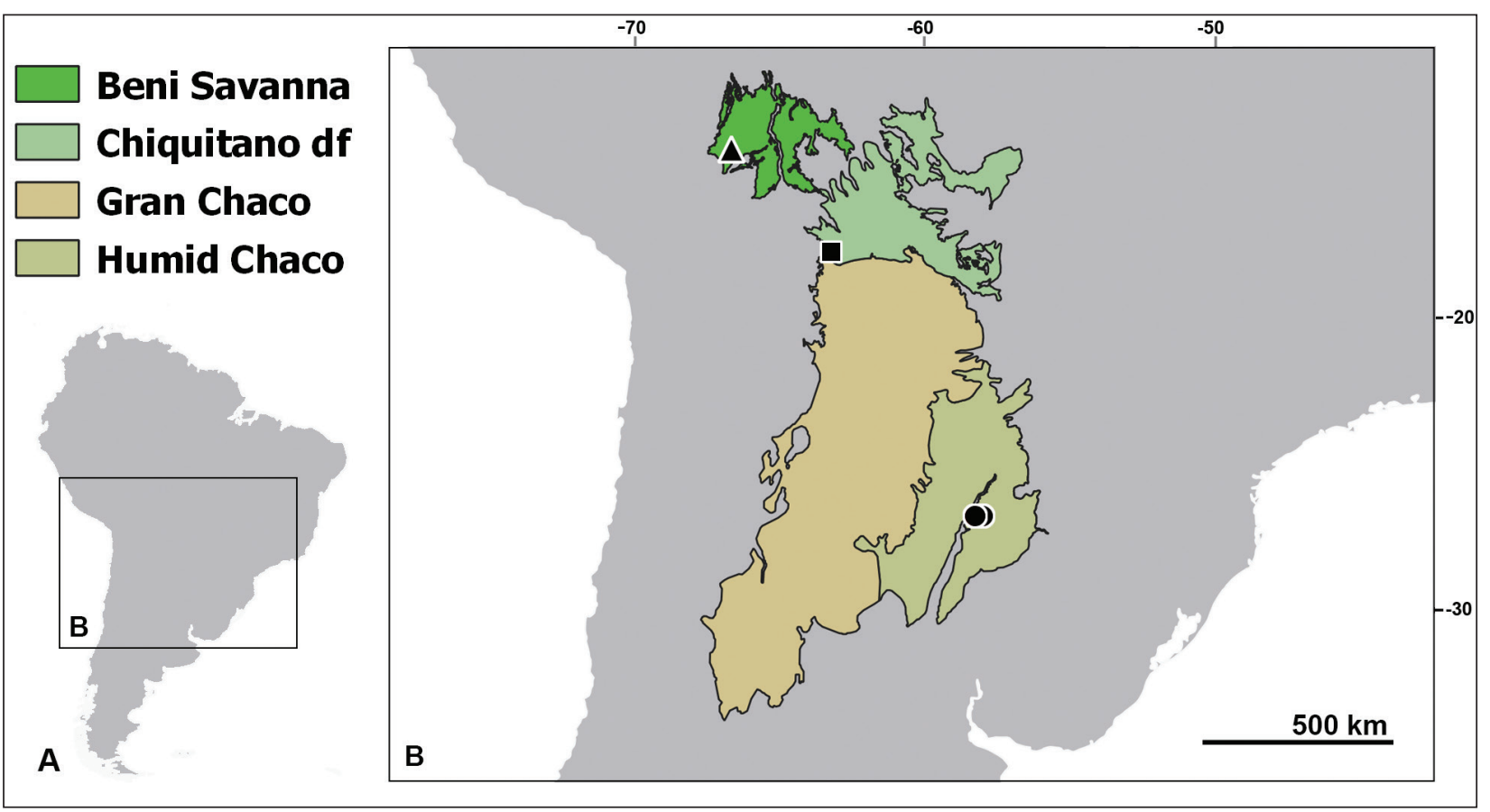

Figure 1. Ecoregion affinities of Grismadox gen. nov. spp. Circle = G. karugua sp. nov., G. mboitui (Pett, 2021); triangle = G. baueri sp. nov.; square $=G$. mazaxoides (Perger \& Dupérré, 2021); $\mathrm{df}=$ dry forest; type locality of G. mazaxoides is considered to be situated in Gran Chaco by Olson et al. (2001) and Chiquitano dry forest by Navarro and Ferreira (2007).

Ciencias Naturales "Bernardino Rivadavia". The letter ' $\mathrm{x}$ ' is taken from the suffix of the genus Mazax with which Grismadox gen. nov. shares some characteristics. Gender is masculine.

Diagnosis. Grismadox gen. nov. can be separated from all other castianeirine genera by the combination of: (i) COs anterior to ST, (ii) male palp with two distinct RTAs, (iii) an embolus with several coils, (iv) a relatively continuous (not constricted) carapace, and (v) an elongated abdomen.

Comparisons. Considering carapace and abdomen shape, arrangement and number of tibia I spines, and the petiolated pedicel, Grismadox gen. nov. is morphologically intermediate between Myrmecotypus and Mazax (see Perger and Dupérré 2021 for comments on G. mazaxoides comb. nov.). Particularly the carapace shape, elongated and constricted abdomen, and the sclerotized second pair of pedicellate setae indicate species of Grismadox gen. nov. are closely related to those of Mazax. However, species of Mazax have AME smaller than ALE, a distinctly elongated and rugose petiole and COs posterior to ST I.

Grismadox gen. nov. can be reliably differentiated from Myrmecotypus and Mazax, and other Neotropical castianeirines, by markedly different copulatory structures: embolus with an irregularly multi-coiled screw shape at its apex, coupled with two conspicuous retrolateral apophyses on the palpal tibia, and copulatory openings anterior to the secondary spermathecae. Myrmecotypus jasmineae Leister \& Miller, 2014a is the only species of the genus with an embolus with several coils (female not known) (cf. Reiskind 1969; Leister and Miller 2014a;
Pett 2021), but it lacks distinct RTAs and an elongate abdomen. Grismadox gen. nov. have elongate abdomens and are ground-dwelling, in contrast with the subglobose abdomens and arboreal habits as in Myrmecotypus. Additionally, Myrmecotypus does not have the second pair of pedicellate setae sclerotized into spines.

Grismadox gen. nov. and some species of Castianeira share the multi-coiled embolus tip and elongated abdomens. However, Castianeira have straight to procurved AER, COs posterior to ST II, and are without dRTA (although some do have a vRTA or a ventral retrolateral protrusion).

Grismadox gen. nov. shares the general habitus, the arrangement of the eyes with the wide and recurved posterior row, strong dorsal scutum on a constricted abdomen with Apochinomma, but can be easily distinguished from this genus by not having a pronounced abdominal petiole a lower number of anterior tibial spines (in Grismadox 2-2, 3-2 or 3-3, in Apochinomma 4-4 or 5-5).

Some species of Myrmecium and Sphecotypus niger (Perty, 1833) have male palps with an embolus with several coils and distinct RTAs. Additionally, a few species of Myrmecium have anterior positioned COs. However, these genera have a very distinctly constricted carapace (Leister and Miller 2014b; Candiani and Bonaldo 2017).

Other genera with a recurved PER and elongate abdomens include the misplaced Afrotropical species of Corinnomma Karsch, 1880 (Haddad 2006; Raven 2015), but Grismadox gen. nov. has a strongly recurved PER vs. slight, and dRTA and vRTA on the male palpal tibia (vs. absent in those Corinnomma spp.). The monotypic Solomon Islands endemic Melanesotypus Raven, 2015 shares with 
Grismadox gen. nov. a recurved PER and anterior lateral extremities of carapace subtruncate in females, but has a subglobose abdomen as in Myrmecotypus. Additionally Melanesotypus has a paracymbial spine on the palp of males, no RTAs, in addition to a wide embolic ridge that arises prolaterally leading into a broad sweeping embolus (Raven 2015), all absent in Grismadox gen. nov.

Description. Small, slender spiders with adults between $3.17 \mathrm{~mm}$ and $6.20 \mathrm{~mm}$ total length. Carapace generally ellipsoid, truncated at posterior margin, with distinct subrectangular cephalic region (more rectangular in females). Carapace sloping very gently towards highest point, at posterior half of the fovea. PER wider than AER, recurved; eyes subequal, with AMEs only slightly larger than ALEs, maximally about $1.3 \times$ diameter of ALEs; AER recurved. Sternum shield-shaped, between $1.5 \times$ to $2 \times$ longer than wide, widest between coxa I and II, anterior ridge of sternum truncated to weakly recurved. Abdomen ovoid, longer than wide, drop-shaped in males, pear-shaped (broader posteriorly) in females. Second pair of pedicellate setae thickened into spines. Abdomen constricted at around 1/3 its length. Ventral sclerite present in males, rectangular and covering around $1 / 2$ total length of venter, just posterior to epigastric sclerite, absent in females. Palpal tibia wider than long, with two RTAs, vRTA disto- laterally oriented at between 10'30 to 11'o clock position and longer, dRTA more distally oriented and shorter. Cymbium with basal retrolateral groove that mirrors angle of vRTA. Sperm duct with convoluted median basal loop and more distal wider retrolateral loop. Embolus screw-like, with between two-and-ahalf and five clear irregularly to tightly spaced coils before tapering to embolic apex, apex varies from translucent and relatively blunter (as in G. karugua sp. nov.) to well-sclerotized and sharp (all other species). Epigynal plate well-sclerotized. Epigyne relatively simple, ST conspicuous and dark, CO situated anterior to ST, ranging from far anterior (G. karugua sp. nov. and G. mazaxoides) to anterolateral (G. mboitui). Both ST spherical. ST II larger than ST I.

Composition. Grismadox baueri sp. nov., Grismadox karugua sp. nov. (type species), Grismadox mazaxoides (Perger \& Duperré, 2021) comb. nov. and Grismadox mboitui (Pett, 2021) comb. nov.

Geographical and ecological distribution. The species of this genus are currently known from the Humid Chaco in southwestern Paraguay and two savanna locations in the area of Chiquitano dry forest and Moxos Plains Flooded Savannas in Bolivia. Judging from observations of live individuals (Perger and Dupérré 2021) and the occurrence in pitfall samples of G. mboitui comb. nov. (Pett 2021a), and G. karugua comb. nov. (this paper), species of this genus appear to be epigeal.

Type material examined for comparison. Mazax ramirezi Rubio \& Danişman, 2014: 1185, figs 1A-F, 2AD, 3A-F, 4A-G, 5A-F (Paratypes $\delta$ and $q$ from ArGENTINA: Buenos Aires, Campana, January 1998, Fuentes \& Di Iorio leg (MACN-Ar 30733/30734).

Myrmecotypus haddadi Perger \& Rubio, 2021. Holotype $\delta$ from Bolivia: Santa Cruz department, Santa Cruz de la Colina, Urubo (-17.760833, -63.24), $432 \mathrm{~m}$ a.s.1., 21 Dec 2019, R. Perger leg. (ZMH-A0015356). Paratypes: $1 \hat{\partial}$, same data as holotype (ZMH-A0015357). 1 ऽ, 1 ㅇ, Santa Maria la Antigua (-17.3719, -63.6563), 13 Apr 2018, R. Perger leg. (IBSI-Ara 1463).

Myrmecotypus rubrofemoratus Perger \& Rubio, 2021. Holotype $\delta$ (IBSI-Ara 1507) and $q$ allotype (IBSI-Ara 1467): Bolivia: Santa Cruz department, (-17.469167, -63.6925), 20-22 Jan 2016, R. Perger leg. Paratypes: same data as holotype, 1 + (IBSI-Ara), 3 + (CBF).

Myrmecotypus tahyinandu Perger \& Rubio, 2020. Holotype $\delta$ from Bolivia: Santa Cruz department: Andrés Ibáñez province, La Guardia (-17.8830, -63.3177), 9 Sep 2015, R. Perger leg. (IBSI-Ara1469). Paratypes: Santa Cruz department: Andrés Ibáñez province: 1 ก, 3 \% , same location as holotype, between Sep 2015 and Jan 2017 (IBSI-Ara1465). 5 गे, 6 ㅇ, same location as holotype, between Sep 2015 and Jan 2017 (CBF). 4 ふ, 5 q, Cotoca (-17.7736, -63.065), 11 Jul 2018, R. Perger leg. (CBF). 1 $\widehat{\jmath}, 1$ 으, Santa Cruz de la Colina (-17.758889, -63.241667), 3 Mar 2019, R. Perger leg. (CBF); 1 ふૈ, 2 q, Arroyo Urubo (-17.7575, -63.251667), 15 Feb 2020, R. Perger leg. (CBF); Lomas de Arena (-17.925, -63.160833), 14 Feb 2020, R. Perger leg. (CBF). Santa Cruz department:

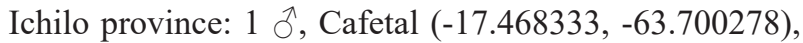
20-22 Jan 2016, R. Perger leg. (CBF).

Myrmecotypus iguazu Rubio \& Arbino, 2009. Holotype $\delta$ (MACN-Ar 19708) and allotype $q$ (MACN-Ar 19709) from ARgENTINA: Misiones Province, Iguazú National Park $\left(25^{\circ} 41^{\prime} \mathrm{S}, 5^{\circ} 26^{\prime} \mathrm{W}\right), 8$ January 2009 , G. Rubio and M. Arbino leg. Paratypes: same locality, 15 January 2005, G. Rubio leg., 1 సै (CARTROUNNE 7818); same locality, 8 January 2009, G. Rubio and M. Arbino leg. 1 ô (CDA 000.806), 3 ㅇ (CDA 000.807, CDA 000.808, CDA 000.810), 1 q (MLP 17926); same locality, 20 January 2005, G. Rubio leg. 1 ภ (CDA 000.811); Misiones

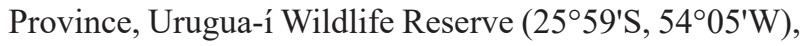
7 March 2009, G. Rubio leg., 1 † (CDA 000.809).

Key to the species of Grismadox gen. nov.

1 Males

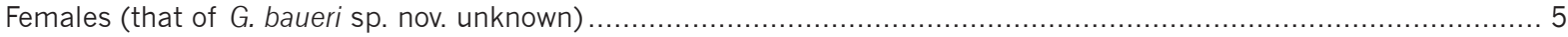

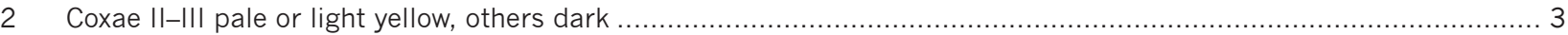

- Coxae II-IV pale or light yellow, other dark..... G. baueri sp. nov. 


\section{Grismadox karugua sp. nov.}

http://zoobank.org/9EE84FF4-0803-487E-8997-97C7097007E2 Figs 2-11

Type material. Holotype: $q$ - PARAguaY: Ñeembucú, Estancia Santa Ana, 26 $50^{\circ} 16.9^{\prime \prime S}, \quad 58^{\circ} 01^{\prime} 42.7^{\prime \prime} \mathrm{W}$, 07.ii.2020-13.ii.2020, Pitfall traps "Grassland", Brogan L. Pett \& Rufus Wyer leg. (CIPLT-Ar 302). Paratypes: PARAGUAY• 1O; Ñeembucú, Estancia Santa Ana, 30.i.2020-06.ii.2020, co-ordinates same as HT, Pitfall traps "Grassland", Brogan L. Pett \& Rufus Wyer leg. (CIPLT-Ar 300_A). • 1 $\delta^{\lambda}$ Ñeembucú, Pilar Military Base, 26 50'28.3"S, 58 18'43.6"W, 28.i.2020-16.ii.220, Pitfall traps “Grassland", Brogan L. Pett \& Rufus Wyer leg. (CIPLT-Ar 305).

Diagnosis. Separated from congeners by: embolus that coils four times (vs. three, four-and-a-half, or five) (Figs 10, 11); embolic apex translucent and relatively blunt (vs. sharp and sclerotized); obvious constriction between ST I and ST II (vs. absent or moderate) (Figs 6, 7); carapace color dark brown to black (with greyish tinge, orangish or yellowish in congeners) (Figs 2, 3); coxae II and III light in both sexes (II-IV light in females of $G$. mazaxoides comb. nov. and G. mboitui comb. nov., female of $G$. baueri sp. nov. not known) (Figs 2-5, 8, 9); tibia I spines 3-3 (2-2 or 3-2 in congeners).

Etymology. The species epithet is a noun in apposition, and refers to the Guarani word for Wetland "karugua". This refers to the Neembucú wetland complex, where the species was discovered.

\section{Description. Female holotype. Figs 2-7.}

Measurements: TL 5.83, CL 2.64, CW 1.30, CH 0.92, CI 49, AL 3.19 (incl. pedicel), AW 1.58, AI 50, SL 1.04, SW 0.59, SI 57. Legs. I: $1.18,0.43,1.04,0.86,0.65$. II: $0.97,0.32,0.73,0.76,0.59$. III: $1.05,0.38,0.89,0.97$, 0.57. IV: $1.50,0.54,1.43,1.38,0.76$. Eyes. AME 0.10, ALE 0.09, PME 0.07, PLE 0.08.

Colouration: Carapace dark brown with heavy black mottling, light orange mottling posteriorly and anteriorly but not medially. Sparse short white setae present in a chevron converging and reaching highest concentration just anterior to the fovea. Base of chelicerae darkest part of cephalothorax. Legs dark orange to brown, granulate. Coxa I and IV dark brown, II and III pale. Sternum orangish-brown with mottled black patches. Abdomen uniform black, with deep red- brown on epigastric sclerite. Rings of white feathery setae in constriction groove and just posterior to epigastric sclerite. Carapace: Generally ovoid, longer than wide by about $2 \times$. Highest point at posterior foveal bump, sloping proximally toward base in lateral view. In dorsal view, carapace moderately truncated anteriorly, with weak curve around cephalic region. Sternum: Distinctly shield-shaped, granulated, widest between coxa I and II. Anterior ridge truncated. Eyes: Anterior eye row moderately recurved, with ALEs and AMEs less than half an AME diameter apart. Posterior eye row nearly straight in frontal view, clearly recurved in dorsal view, PMEs smallest. Legs: Femora with strong, long dorsal spine. Femoral spine IV longer than femoral spine III, III longer than II, and femoral spine on leg I with damaged spines on both legs. However, in paratype female spine of F II larger than spine F I. Chelicerae: Small lateral condyle. Two teeth on retromargin, distal tooth larger. Promargin with two teeth, distal tooth much larger than teeth on retromargin and other promarginal tooth, basal tooth about $3 \times$ distal tooth width away from distal tooth and much smaller. Strong promarginal rake setae obscure fang and cheliceral furrow teeth. Abdomen: Twice as long as it is wide, dorsal scutum convex and covering between $1 / 4$ and $2 / 3$ of abdomen, shiny and granulated. Second pair of pedicellate setae sclerotized into pair of straight spines at anterior part of scutum, running subparallel to bulbous part of scutum. Clear constriction of abdomen around 1/3 of length, distinct when viewed laterally, ring of white longitudinally flattened short feathery setae in region of constriction, almost absent dorsomedially, densest venterolaterally. Another ring of short feathery white feathery setae present just posterior to spines at the dorsal scutum. Ventral sclerite absent, pale outline of venter clearly not concolorous with rest of abdomen. Concentrated patches of short, fluffy white setae in anterolateral corners of epigastric furrow. Inframamillary sclerite very small, dark brown, epigastric sclerite anteriorly forming petiole, dark brown to black, with moderately lighter orange and red mottling. Epigyne (Figs 6, 7). Epigynal plate relatively small. Epigyne with widely spaced copulatory openings anterior to ST. CD horn-like, travelling medially first before reaching spermathecae, $\mathrm{CD}$ then tapering laterally from midpoint. ST II touching medially, spherical and diverging posterolaterally into ST I. ST I much smaller and oval, projected laterally, FD arising at ST I anteromedially. 

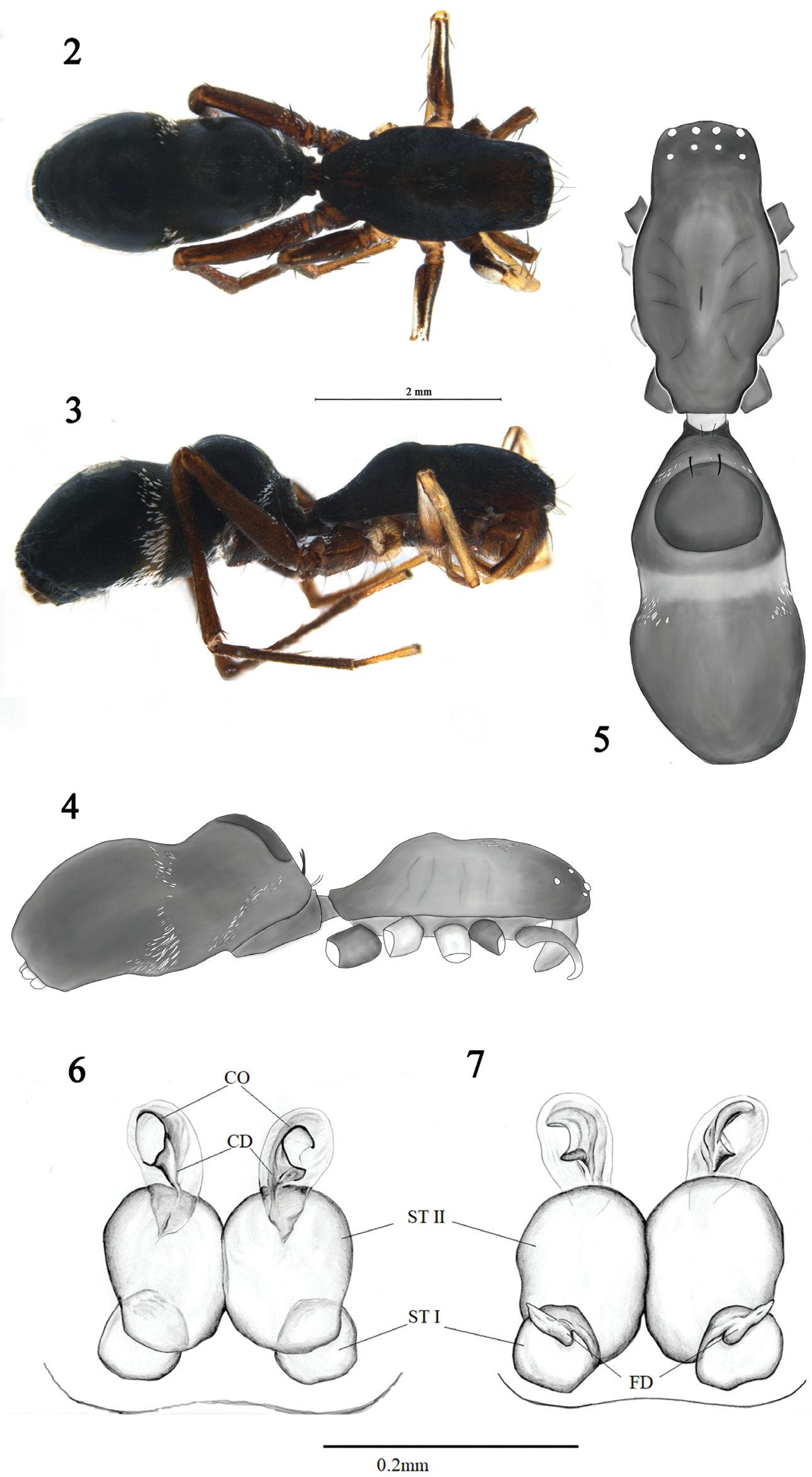

Figures 2-7. Grismadox karugua sp. nov. female holotype (CIPLT-Ar 302) habitus. 2. Micrograph dorsal; 3. Micrograph lateral; 4. Drawing lateral; 5. Drawing dorsal. Figs 6, 7. cleared female epigyne. 6. Ventral; 7. Dorsal. 

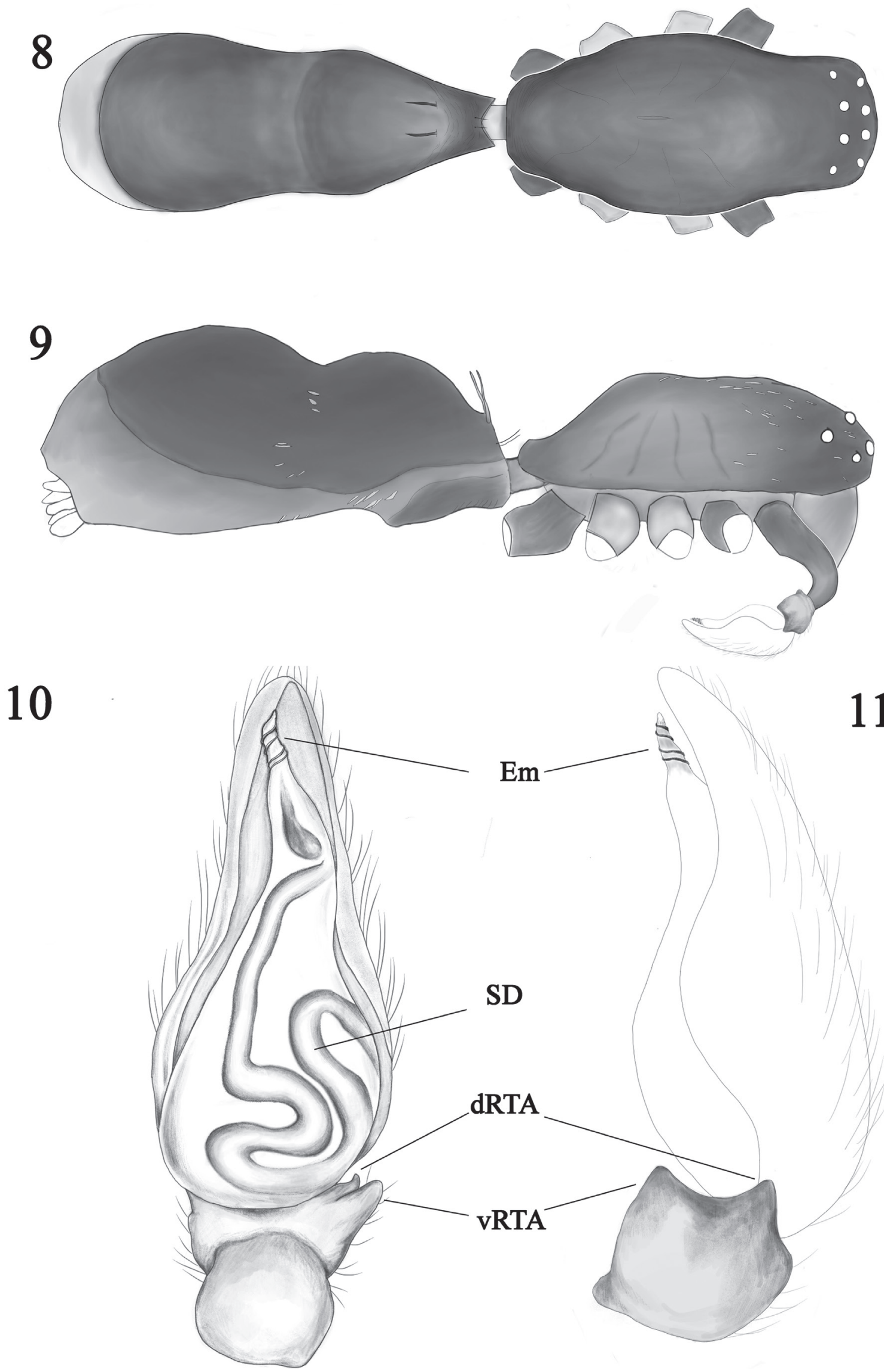

11

Figures 8-11. G. karugua sp. nov. male paratype habitus and pedipalp (CIPLT-Ar 305). 8. Dorsal; 9. Lateral; 10. Pedipalp ventral; 11. Pedipalp retrolateral. $\mathrm{dRTA}=$ dorsal retrolateral tibial apophysis, $\mathrm{Em}=$ embolus, $\mathrm{SD}=$ sperm duct, $\mathrm{vRTA}=$ ventral retrolateral tibial apophysis. 
Leg spination. $\mathrm{I}: \mathrm{F}=\mathrm{p} 11 \mathrm{~d} 1, \mathrm{Ti}=\mathrm{v}=3-3(\mathrm{plv} 3 \mathrm{rlv} 3)$, $\mathrm{mt}=2-2($ plv 2 rlv 2$) . \mathrm{II}: \mathrm{F}=\mathrm{d} 2, \mathrm{Ti}=3-3(\mathrm{plv} 3 \mathrm{rlv} 3), \mathrm{mt}$ $=2-2($ plv2 rlv2). III: $\mathrm{F}=\mathrm{d} 2, \mathrm{pl} 1, \mathrm{P}=\mathrm{d} 1, \mathrm{Ti}=\mathrm{d} 1 \mathrm{pl} 2 \mathrm{rl}$, $\mathrm{mt}=2-2-2-2(\mathrm{pl} 2 \mathrm{rl} 2 \mathrm{plv} 2 \mathrm{rlv} 2) 1$ distal whorl, IV: $\mathrm{F}=\mathrm{d} 2$ $\mathrm{pl}, \mathrm{P}=\mathrm{d} 1, \mathrm{Ti}=\mathrm{d} 2 \mathrm{pl} 13-3(\mathrm{plv} 3 \mathrm{rlv} 3), \mathrm{mt}=\mathrm{d} 22-2(\mathrm{plv}$ 2 rlv2) 1 distal whorl.

Male paratype. Figs 8, 9. Measurements. TL 4.54, CL 2.11, CW 1.08, CH 1.09, CI 51, AL 2.43 (incl. pedicel), AW 1.00, AI 41, SL 1.62, SW 0.97, SI 60. Chelicerae length 0.51 , chelicerae width 0.30 . Legs. I: $0.97,0.28$, $0.84,0.80,0.65$. II: Missing. III: 0.95, 0.30, 0.76, 0.86, 0.51 . IV: $1.27,0.31,1.27,1.35,0.68$.

Habitus shape, leg formula, spination and general color pattern as in female, male carapace brighter, primarily orangish-brown. Dorsal scutum large, around 3/4 of AL, strong spines on anterior part of dorsal scutum projected posteriorly at 30-45 degree angle, abdominal constriction slight but conspicuous in lateral view, posterior to dorsal scutum. Few short white feathery setae dorsally and laterally at site of constriction and just posterior to spines of dorsal scutum. Ventral sclerite present, clearly defined, covering around $1 / 2$ of venter just posterior to epigastric sclerite, inframamillary sclerite very small, dark brown.

Palp: Spination: femur $=v_{\mathrm{v}}$, , patella $=\mathrm{v} 2$ pl 1, tibia $=\mathrm{v}$ $1 \mathrm{pl} 1$. Tibial spines substantially larger than others, with $\mathrm{pl}$ spine about 1.5 times the length of $\mathrm{pl}$ ventral spine. Palpal bulb with basally convoluted median loop in sperm duct, second, wider, more distal retrolateral loop. Palpal tibia with two short pointed retrolateral apophyses, ventral one projected disto-laterally at $11^{\prime} 00$ position, dRTA shorter and more distally oriented, with tip recurving weakly back towards palp. Embolus screw-like, with three irregularly spaced coils, apical two crossing over, before tapering to pale apex.

Geographical and ecological distribution. This species is only known from the type locality in Estancia Santa Ana, Ñeembucú wetland complex, Paraguay. According to the ecoregion delineation by Olson et al. (2001), the locality is situated in Humid Chaco. The habitat in which G. karugua sp. nov. was collected was savanna-like grassland. Judging from the occurrence in pitfall samples, the species is epigeal.

\section{Grismadox baueri sp. nov.}

http://zoobank.org/1EB5BA81-86AF-48C3-B0FF-040C722F4D6F Figs $12-15$

Type material. Holotype ふึ; • Bolivia: Beni department, Ballivian, Espiritu, 14²12'57.6"S, 66³9'57.6"W), vegetation, 22.5.1986, W. Hanagarth, J. Sarmiento leg. (SMNK-ARA 13505).

Diagnosis. Separated from congeners by: coxae IV in male light (vs. dark) (Figs 12, 13); tibia I spines 2-2 (vs. 3-2 or 3-3); lateral anterior extremities of carapace smooth (vs. squared); embolus with five coils (vs. three - four and a half), apex sharp (vs pointed or blunt); dRTA that arises at wider position in ventral view (vs. closer to the palp in others) (Figs 14, 15); much smaller size than adult male of other species (3.17 mm vs. 4.50-5.80); weak constriction of abdomen (vs. clear constriction); sternum index 78, i.e. a broader sternum (much higher than other species).

Etymology. The species epithet is a genitive patronym in honor of German arachnologist Tobias Bauer, of SMNK, for initially facilitating the loan of the holotype of this species and for many instances of arachnological assistance to the first author.

Description. Male holotype. Measurements: TL 3.17, CL 1.52, CW 0.84, CI 55, CH 0.94, AL 1.65 (incl. pedicel), AW 0.72, AI 47, SL 0.64, SW 0.50. SI 78, Chelicera length 0.38 , width 0.22 . Legs. I: $0.94,0.20,0.80,0.78$, 0.70. II: $0.90,0.16,0.78,0.74,0.58$. III: $0.80,0.24,0.66$, $0.76,0.54$. IV: $1.12,0.30,1.10,1.18,0.68$. Eyes. AME 0.07, ALE - 0.05, PME - 0.05, PLE - 0.06.

Colouration: In ethanol (c. 1986). Carapace orange with black mottling in lines leading from fovea to carapace margins. Small patch anterior to fovea discolored, potentially harboring setae prior to preservation. Black eye rings, darkest around AMEs. Chelicerae concolorous with carapace. Legs light brown to pale from patella I and II, legs III and IV consistently pale medially with brown margins. Coxae I darker, other three white. Sternum orange with distinct darker stripes converging medially. Abdomen darker orange than carapace, darker at anterior $1 / 3^{\text {rd }}$ due to moderate sclerotization.

Carapace: Oval, longer than wide by about two times. Very weak depression between fovea and cephalic region, otherwise of uniform height, before sloping proximally towards base in lateral view.

Sternum: Distinctly shield-shaped, relatively broad, $0.8 \times$ the length, anterior ridge truncated, widest between coxa I and II. Distinct dark stripe markings beginning adjacent to coxae, converging medially.

Eyes: AER slightly recurved, AMEs largest and black, nearly touching ALEs. PER wider than AER by about 1.4×, PER moderately recurved.

Legs: Femora with strong dorsal spine, all equal length. Femora I and II streaked brown and pale, rest of segments pale, legs III and IV streaked throughout. Short, fine setae throughout.

Chelicerae: Promargin with two teeth, distal almost twice as large. Retromargin with two small teeth, both smaller than smaller promargin tooth. No chilum, lateral condyle not visible.

Abdomen: Drop-shaped, much longer than wide, $2.5 \times$. Dorsal scutum almost entire. Anterior $1 / 3^{\text {rd }}$ moderately sclerotized, more than scarcely sclerotized posterior $2 / 3^{\text {rd }}$ s. Weak constriction at $1 / 3^{\text {rd }}$, constriction paler, constriction clear when viewed in lateral but is almost indistinct in dorsal view. Second pair of pedicellate setae sclerotized into moderate spines at anterior margin projected at 2' o clock position when viewed laterally. Two strong setae (much weaker than spines) present, just anterior to spines and projected at 2'30 position when viewed laterally. Large ventral sclerite occupying $2 / 3$ length of venter, barrel-shaped and with recurved posterior margin. Small 


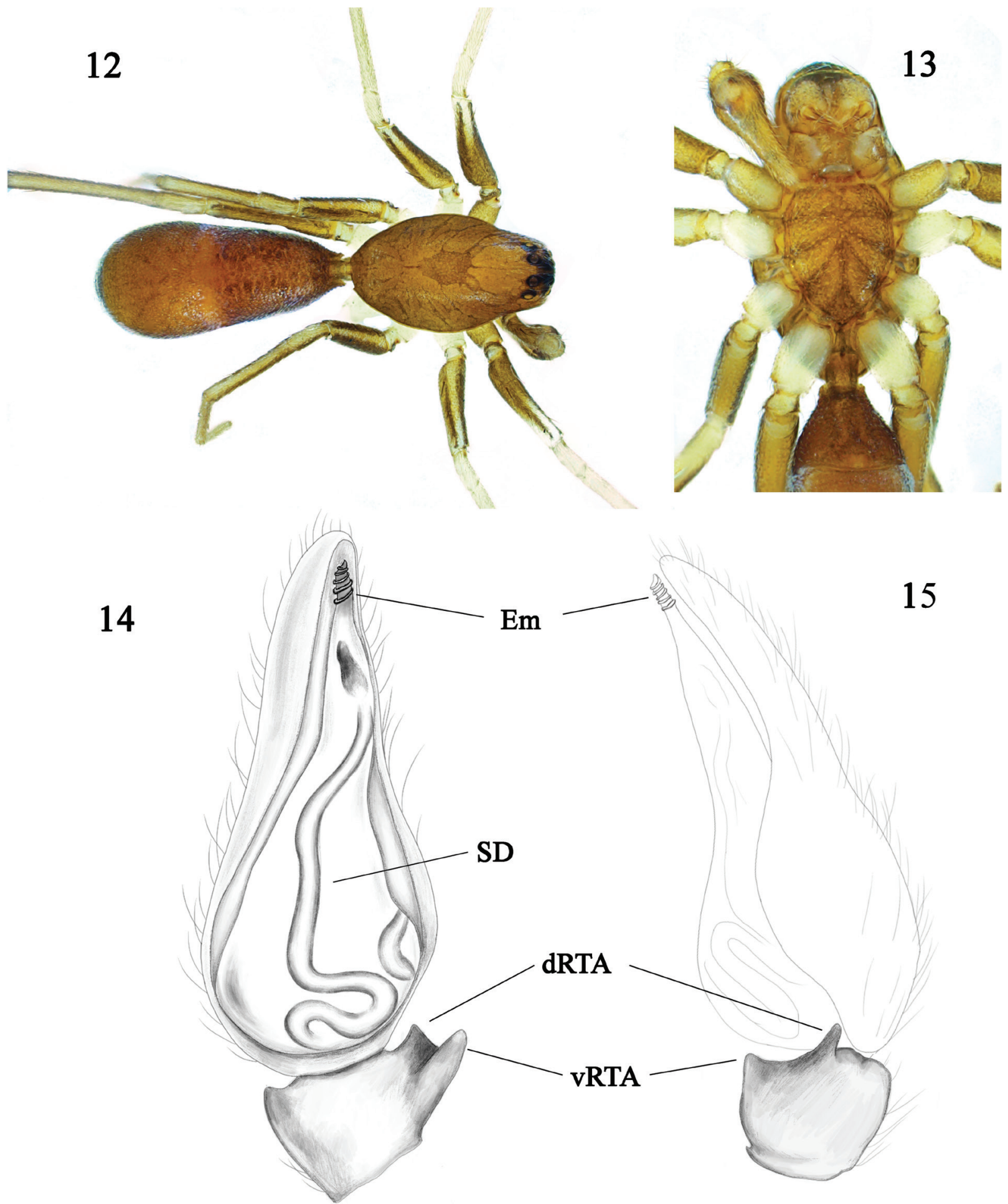

Figures 12-15. Grismadox baueri sp. nov. male holotype (SMNK-ARA 13505). 12. Habitus dorsal; 13. Ventral aspect of carapace; 14. Pedipalp in ventral; 15. Pedipalp in retrolateral. $\mathrm{dRTA}=$ dorsal retrolateral tibial apophysis, $\mathrm{Em}=$ embolus, $\mathrm{SD}=\mathrm{sperm}$ duct, vRTA $=$ ventral retrolateral tibial apophysis.

patches of white setae at anterior lateral margin of ventral sclerite, bordering posterior lateral edge of epigastric sclerite. Ventral and epigastric sclerites contiguous.

Palp: Tibia with two RTAs, dRTA more pointed than blunter vRTA. In retrolateral view, dRTA apex points ventrally. Embolus relatively thick and elongate, with five coils; three coils from apical third, basal two coils are much wider. Final coil slimmer.
Leg spination: $\mathrm{I}: \mathrm{F}=\mathrm{p} 11 \mathrm{~d} 1, \mathrm{~T}=(2-2) \mathrm{plv} 2 \mathrm{rlv} 2, \mathrm{Mt}=$ (2-2) plv2 rlv2. II: $\mathrm{F}=\mathrm{d} 1, \mathrm{~T}=(1-1) \mathrm{plv} 1 \mathrm{rlv} 1, \mathrm{Mt}=(2-2)$ plv2 rlv2. III: $\mathrm{F}=\mathrm{d} 2, \mathrm{~T}=\mathrm{pl} 1 \mathrm{rl}$ plv1, $\mathrm{Mt}=(2-2)$ plv2 rlv2. IV: $\mathrm{F}=\mathrm{d} 2, \mathrm{~T}=(2-2) \mathrm{plv} 2 \mathrm{rlv} 2, \mathrm{Mt}=\mathrm{pl} 2 \mathrm{rl} 1 \mathrm{plv} 2 \mathrm{rlv} 1$.

Geographical and ecological distribution. This species is only known from the type locality in Espiritu, José Ballivián province, Beni Department, Bolivia. According to 
the ecoregion delineation by Olson et al. (2001), the locality is situated in Beni savanna (widely recognized as Moxos Plains Flooded Savannas, see Ibisch and Merida 2003). This savanna is comprised of a mosaic of grasslands, swamplands and forest islands (Navarro and Ferreira 2007). Based on the approximated GPS data of the collection locality (according to the information by the owner of Espiritu ranch), it was not possible to determine the accurate ecosystem or habitat associations of G. baueri sp. nov. Further studies are needed to determine the latter.

\section{Grismadox mazaxoides (Perger \& Dupérré, 2021) comb. nov.}

Myrmecotypus mazaxoides (Perger \& Duperré, 2021). 275, figs. 2A, B, 3A, B, 4A-E, 5A, B, 6A, B, 7A, B. Male holotype (ZMH), male and female paratypes (ZMH and $\mathrm{CBF}$ ) from Santa Cruz department, Bolivia, examined.

Type deposit. Holotype $\delta$ and $q$ allotype:

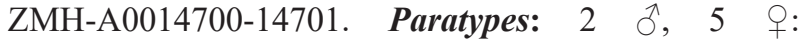
ZMH-A0014707; 6 ऽ, 10 ㅇ: CBF.

Diagnosis. Separated from congeners by: an embolus that coils three times (vs. between four and five times); dRTA that is blunter and translucent (vs. more pointed); constriction between ST I and ST II absent (vs. present, female of $G$. baueri sp. nov. unknown); carapace color with grayish tinge (dark brown to black, orangish or yellowish in congeners).

Description. See: Perger and Dupérré (2021).

Geographical and ecological distribution. Epigeal in Cerrado-like grassland or savanna habitats. According to Navarro and Ferreira (2011), the type locality of this species is situated in Chiquitano forest, while Olson et al. (2001) consider this area Gran Chaco. Judging from the observation of this species in open areas, the species is likely to occur in the Gran Chaco area.

\section{Grismadox mboitui comb. nov. (Pett, 2021)}

Myrmecotypus mboitui (Pett, 2021) 79, figs 3-13. Male holotype and female paratypes (CCPLT) from Ñeembucú department, Paraguay, examined.

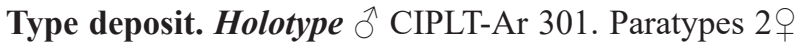
CIPLT-Ar 303, 1 을 CIPLT-Ar 300.

Diagnosis. Separated from congeners by: pedipalp with four and a half coils (vs. three, four or five); RTAs in ventral view much larger than that of other species; constriction between ST I and ST II moderate (vs. absent or distinct); COs slightly anterolateral to ST (vs. far anterior); carapace orangish (vs. dark brown to black, greyish or yellowish).

Description. See: Pett (2021).
Geographical and ecological distribution. Epigeal in savanna-like wetland in the Humid Chaco area.

Etymological notes. G. mboitui was named after the Guaraní mythological figure Mbói tu'ĩ, and all details of the specific epithet are accurate. However, it was incorrectly stated in parentheses of the etymology section that Mbói = parrot and tu' $\tilde{1}=$ snake (in Guaraní), when in fact this was an incorrect transcription and the opposite is true. Mbói $=$ snake and tu'ĩ = parrot.

\section{Discussion}

All Grismadox species for which we have detailed records were collected in savannah-like habitat (e.g., seasonally inundated grasslands in Humid Chaco, as in Paraguayan species). The discovery of numerous new species in this habitat in Paraguay and Bolivia illustrates a strong negative sampling bias against Neotropical savannah-like habitats. Indeed, even limited sampling such as in the short pitfall trapping project in the Ñeembucú wetland complex (see: Pett 2019; Pett and Wyer 2020; Pett 2021a, b; Pett et al. 2021) or manual sampling in a Bolivian savanna mosaic (Perger and Dupérré 2021; Perger and Rubio 2021), yielded numerous taxonomic novelties, including three of the species presented here, among other undescribed taxa. It is also of note that two sympatric Grismadox exist in the same site in the NWC and at the present time their ecological separation is based on relatively little data but appears to correspond to a forest/grassland edge specialist (G. mboitui comb. nov.) and a grassland specialist species (G. karugua sp. nov.).

The conservation value of such regions is barely understood in terms of their invertebrate taxa (Rubio et al. 2018; Dickens et al. 2020). We therefore stress the urgent need for further arthropod collections in Neotropical savannahs and wetland regions.

\section{Acknowledgements}

Extensive thanks are due to Rufus Wyer, co- collector of the type specimens of the type species. Additional thanks are due to Varvara Vladimirova (Université Laval) and Jack McBride for assistance in the field during the pitfall trapping project in Paraguay. Thanks also to Fundación Para La Tierra for supporting the project through provision of resources during the pitfall trapping project in Paraguay, to Don Odilon Barrios for allowing the pitfall trap project at Estancia Santa Ana, and to the staff at the Coronel Alberto Torres Nuñez for access to the Regimiento de Caballeria No 2 "Colonel Felipe Toledo". The Ministerio del Ambiente y Desarrollo Sostenible granted research permits to the CCPLT for Paraguayan specimens. Thanks to Jorge Ayala Damian Santacruz for assisting in Guaraní translation. Thanks to Tobias Bauer and Hubert Höfer (both SMNK) for facilitating loans of Neotropical castianeirine material to the first author, including the holotype of one of the new species. Additionally, 
Zoë Simmons is thanked for allowing BLP to use the automontage system at Oxford University Museum of Natural History (OUMNH) during a research visit. Charlotte Lawlor (Falmouth University) made the fantastic pedipalp drawings of both new Grismadox species for which we are extremely grateful. Amanda Morgan Riley (www.amandarileyart.com) is thanked for epigyne illustration of G. karugua. We extend sincere thanks to reviewers Dr. Charles R. Haddad (University of the Free State) and Dr. Martín Ramírez (Museo Argentino Ciencias de Naturales) for substantially improving the manuscript. Subject editor Dr. Danilo Harms (Universität Hamburg) is thanked for handling the manuscript.

\section{References}

Cala-Riquelme F (2021) Autodesk Sketchbook: An application that minimizes time and maximizes results of taxonomic drawing. Zootaxa 4963(3): 577-586. https://doi.org/10.11646/zootaxa.4963.3.10

Candiani DF, Bonaldo AB (2017) The superficial ant: a revision of the Neotropical ant-mimicking spider genus Myrmecium Latreille, 1824 (Araneae, Corinnidae, Castianeirinae). Zootaxa 4230(1): 1-95. https://doi.org/10.11646/zootaxa.4230.1.1

Cushing PE (2012) Spider-ant associations: An updated review of myrmecomorphy, myrmecophily, and myrmecophagy in spiders. Psyche 151989: 1-23. https://doi.org/10.1155/2012/151989

Dickens JK, Schoenberger D, VanCompernolle M (2020) Guide to the Odonata of central Ñeembucú, Paraguay: indicator species of wetland habitats. International Journal of Odonatology 23(3): 239-289. https://doi.org/10.1080/13887890.2020.1768157

Haddad C (2013) A revision of the ant-like sac spider genus Apochinomma Pavesi 1881 (Araneae: Corinnidae) in the Afrotropical Region. Journal of Natural History 47(39-40): 2493-2529. https://doi. org/10.1080/00222933.2013.791933

Ibisch PL, Mérida G (2003) Biodiversidad: La riqueza de Bolivia. Estado de conocimiento y conservación. Ministerio de Desarrollo Sostenible. Editorial Fundación Amigos de la Naturaleza (FAN), Santa Cruz, Bolivia, 638 pp.

Leister M, Miller K (2014a) A new species of ant mimicking spider, Myrmecotypus jasmineae (Araneae: Corinnidae: Castianeirinae), from Nicaragua. Zootaxa 3838(4): 495-500. https://doi. org/10.11646/zootaxa.3838.4.8

Leister M, Miller K (2014b) First description of the male of Sphecotypus niger (Perty, 1833), with notes on behavioral and morphological mimicry (Araneae: Corinnidae: Castianeirinae). Zootaxa 3814(1): 146-150. https://doi.org/10.11646/zootaxa.3814.1.10

Navarro G, Ferreira W (2007) Mapa de Sistemas Ecológicos de Bolivia, escala 1:250000. RUMBOL SRL-The Nature Conservancy (TNC), Bolivia. [Edición CD ROM]

Olson DM, Dinerstein E, Wikramanayake ED, Burgess ND, Powell GVN, Underwood EC, D’Amico JA, Itoua I, Strand HE, Morrison JC, Loucks CJ, Allnutt TF, Ricketts TH, Kura Y, Lamoreux JF, Wettengel WW, Hedao P, Kassem KR (2001) Terrestrial ecoregions of the world: a new map of life on Earth. Bioscience 51(11): 933-938. https://doi. org/10.1641/0006-3568(2001)051[0933:TEOTWA]2.0.CO;2

Pekár S, Jarab M (2011) Assessment of color and behavioral resemblance to models by inaccurate myrmecomorphic spiders (Araneae). Invertebrate Biology 130(1): 83-90. https://doi.org/10.1111/j.17447410.2010.00217.x
Perger R (2021) Are goldish spiders able to teach naïve predators to avoid bullet ants? A possible case of Müllerian mimicry in spiders and ants. Journal of Natural History 55(9-10): 625-627. https://doi. org/10.1080/00222933.2021.1914450

Perger R, Dupérré N (2021) Myrmecotypus mazaxoides sp. nov. - a new ground-dwelling, carpenter ant-resembling sac spider species from the Bolivian orocline, with indirect evidence for species-specific mimicry (Araneae, Corinnidae, Castianeirinae). Zoosystematics and Evolution 97(1): 273-280. https://doi.org/10.3897/ zse.97.64766

Perger R, Rubio GD (2020) Contributions to the knowledge of Neotropical ant-like spiders: Myrmecotypus tahyinandu sp. n. from Bolivian Chiquitano forest, a new country record for $M$. niger, and indirect evidence for species-specific mimicry (Araneae: Corinnidae: Castianeirinae). Zootaxa 4790(1): 151-164. https://doi.org/10.11646/ zootaxa.4790.1.9

Perger R, Rubio GD (2021) Myrmecotypus haddadi sp. nov. - a new species of ant resembling sac spider from the Bolivian orocline (Araneae: Corinnidae: Castianeirinae). Zootaxa 4969(1): 54-60. https://doi.org/10.11646/zootaxa.4969.1.2

Pett BL (2019) First confirmed locality record of Gypogyna forceps Simon, 1900 (Araneae: Salticidae: Salticinae: Scopocirini) from Paraguay. Peckhamia 193.1: 1-3. https://doi.org/10.5281/zenodo. 5414474

Pett BL (2021a) Description of a new species of Myrmecotypus (Araneae: Corinnidae, Castianeirinae), the first of its genus known from Paraguay, with an updated key to species. Zootaxa 4999(1): 77-86. https://doi.org/10.11646/zootaxa.4999.1.5

Pett BL (2021b) First description of the female of Otiothops inflatus Platnick, 1975 (Araneae: Palpimanidae). Revista Ibérica de Aracnología 38: 103-106. https://doi.org/10.5281/zenodo.5361047

Pett BL, Rubio GD, Stolar CE (2021) A first baseline for the salticid (Araneae: Salticidae) fauna of Paraguay, with thirty-two new records and description of a new species from Paraguay and Argentina. Arachnology 18(8): 922-935. https://oi.org/10.13156/ arac.2021.18.8.922

Pett BL, Wyer R (2020) First confirmed record of the genus Cybaeodamus (Araneae: Zodariidae) in Paraguay, with notes on its distribution. Revista Ibérica de Aracnología 36: 161-162. https://doi. org/10.5281/zenodo.5414300

Reiskind J (1969) The spider subfamily Castianeirinae of North and Central America (Araneae, Clubionidae). Bulletin of the Museum of Comparative Zoology 138(5): 163-325.

Rubio GD, Arbino MO (2009) The first Myrmecotypus O. P.-Cambridge (Araneae: Corinnidae) from Argentina: description of $M y r-$ mecotypus iguazu new species. Zootaxa 2158: 65-68. https://doi. org/10.11646/zootaxa.2158.1.6

Rubio GD, Danişman T (2014) The spider genus Mazax (Araneae: Corinnidae: Castianeirinae) newly recorded from South America, with the description of a new species. Florida Entomologist 97(3): 1182-1190. https://doi.org/10.1653/024.097.0325

Rubio GD, Zapata LV, Grismado CJ (2015) A new species of Castianeira Keyserling (Araneae, Corinnidae) from Buenos Aires, Argentina. Studies on Neotropical Fauna and Environment 50(2): 137-143. https://doi.org/10.1080/01650521.2015.1058112

Rubio GD, Nadal MF, Munévar AC, Avalos G, Perger R (2018) Iberá Wetlands diversity hotspot, valid ecoregion or transitional area? Perspective from a faunistic jumping spiders revision (Araneae: Salticidae). Species 19: 117-131. 